\title{
Phase 2 clinical trial of 5-azacitidine, valproic acid, and all- trans retinoic acid in patients with high-risk acute myeloid leukemia or myelodysplastic syndrome
}

\section{Emmanuel Raffoux ${ }^{1}$,Audrey Cras $^{2}$, Christian Recher ${ }^{3}$, Pierre-Yves Boëlle ${ }^{4}$, Adrienne de Labarthe ${ }^{1}$, Pascal Turlure ${ }^{5}$, Jean-Pierre Marolleau ${ }^{6}$, Oumedaly Reman7, Claude Gardin', Maud Victor ${ }^{2}$, Sébastien Maury ${ }^{9}$, Philippe Rousselot ${ }^{10}$, Jean-Valère Malfuson ${ }^{11}$, Odile Maarek ${ }^{1}$, Marie-Thérèse Daniel ${ }^{1}$, Pierre Fenaux ${ }^{8}$, Laurent Degos $^{1}$, Christine Chomienne ${ }^{2}$, Sylvie Chevret ${ }^{12}$, and Hervé Dombret ${ }^{1}$}

\footnotetext{
1 Département d'Hématologie, Hôpital Saint-Louis, Assistance Publique - Hôpitaux de Paris (AP-HP), and Université Denis Diderot - Paris 7, EA 3518, Institut Universitaire d'Hématologie (IUH), Paris;

2 UMR-S-940, Université Denis Diderot-Paris 7, IUH, Paris;

3 Département d'Hématologie, Hôpital Purpan, Toulouse;

4 UMR-S-707, Université Pierre et Marie Curie - Paris 6, Hôpital Saint-Antoine, AP-HP, Paris;

5 Département d'Hématologie, Hôpital Dupuytren, Limoges;

6 Département d'Hématologie, Hôpital Nord, Amiens;

7 Département d'Hématologie, Centre Hospitalier Universitaire, Caen;

8 Département d'Hématologie, Hôpital Avicenne, AP-HP, Bobigny;

9 Département d'Hématologie, Hôpital Henri Mondor, AP-HP, Créteil;

10 Département d'Hématologie, Hôpital Mignot, Versailles;

11 Département d'Hématologie, Hôpital Percy, Clamart;

12 Département de Biostatistiques et d'Informatique Médicale, Hôpital Saint-Louis, AP-HP, Paris, France.
}

Correspondence to: Dr Emmanuel Raffoux, Department of Hematology, Hôpital Saint-Louis,

1 avenue Claude Vellefaux, 75010 Paris, France;

Tel: (33) 142499643, Fax: (33) 142499345, e-mail: emmanuel.raffoux@sls.aphp.fr

Running title: Epigenetic modulation in high-risk AML/MDS

Key words: acute myeloid leukemia, azacitidine, valproic acid, ATRA, FZD9 methylation

Received: April 24, 2010, Accepted: May 6, 2010, Published: on line May 19, 2010

Copyright: C 2010 Raffoux et al. This is an open-access article distributed under the terms of the Creative Commons Attribution License, which permits unrestricted use, distribution, and reproduction in any medium, provided the original author and source are credited.

ABSTRACT:

In this Phase 2 study, we evaluated the efficacy of combination of 5-azacitidine (AZA), valproic acid (VPA), and all-trans retinoic acid (ATRA) in patients with high-risk acute myeloid leukemia (AML) or myelodysplastic syndrome (MDS). Treatment consisted of six cycles of AZA and VPA for 7 days, followed by ATRA for 21 days. Sixty-five patients were enrolled (median age, 72 years; 55 AML including 13 relapsed/refractory patients, 10 MDS; 30 unfavorable karyotypes). Best responses included 14 CR and 3 PR $(26 \%), 75 \%$ of the responders and $36 \%$ of the non-responders achieving an erythroid response. Median overall survival (OS) was 12.4 months. Untreated patients had a longer OS than relapsed/refractory patients. In patients who fulfilled the 6 planned cycles, OS did not appear to depend on CR/PR achievement, suggesting that stable disease while on-treatment would be a surrogate for survival with this approach. During therapy, early platelet response and demethylation of the FZD9, ALOX12, HPN, and CALCA genes were associated with clinical response. Finally, there was no evidence for the restoration of an ATRA-induced differentiation during therapy.

Epigenetic modulation deserves prospective comparisons to conventional care in patients with high-risk $A M L$, at least in those presenting previously untreated disease and low blast count. 


\section{INTRODUCTION}

Chromatine remodeling through DNA demethylation has been investigated for many years as a potential anticancer therapeutic approach [1]. Two DNA methyltransferase inhibitors, 5-azacytidine (AZA) and decitabine, have demonstrated clinical activity as single agents in patients with MDS/AML [2-7]. Both drugs are registered in the US to treat patients with MDS. Based on a large confirmatory study [8], AZA has recently obtained an EMEA approval to treat patients with high-risk MDS and AML until 30\% marrow blasts, as the survival benefit over conventional care regimens was also observed in the subgroup of patients with low bone marrow blast count AML [9].

Another way to modulate the epigenetic chromatine structure is to use histone deacetylase (HDAC) inhibitors. It has been shown for instance that the resistance to all-trans retinoic acid (ATRA) observed in acute promyelocytic leukemia (APL) cells carrying the variant PLZF-RARA fusion protein may be abrogated by HDAC inhibitors (HDACi) such as trichostatin A or sodium phenylbutyrate in vitro or in vivo [10-11]. Valproic acid (VPA) has been demonstrated as belonging to the HDACi family and, interestingly, combined VPA/ATRA treatment may also induce hematological responses in patients with non-APL AML or MDS [12-14].

In this Phase 2 study, we thus evaluated the efficacy of AZA/VPA/ATRA combination in patients with high-risk AML or MDS. Focusing on differential analysis between responders and non-responders, DNA methylation profile analysis confirmed that epigenetic modulation occurs in vivo and may be linked to drug efficacy.

\section{RESULTS}

\section{Patients}

A total of 65 patients (median age, 72 years; ranging from 50 to 87) entered the study. Patient characteristics are shown in Table 1. The numbers of patients were 42, 13, and 10 in eligibility subset 1,2, and 3, respectively. All patients with refractory/relapsed AML had previously received intensive chemotherapy. The proportion of patients with unfavorable cytogenetics was high $(52 \%)$; no patient had favorable core binding factor AML. Median WBC and percentage of marrow blasts were low, suggesting that a selection of patients with slowly progressing disease may have occurred. At the reference date of analysis, the median follow-up was 16.3 months, ranging from 14 to 28 .

\section{Compliance and response}

Details on compliance to therapy, as well as reasons for treatment discontinuation, are given in Table 2. Three patients never started the treatment ( 1 consent withdrawal,
2 very early deaths). The main causes of treatment discontinuation were disease progression ( 8 patients) and death (15 patients). Death was related to or concomitant of disease progression in 5 of these 15 patients. Nine patients died from infection and another one died from myocardial infarction. Only 3 patients withdrew their consent during the study time.

Table 1. Patient characteristics

\begin{tabular}{|l|l|}
\hline \multicolumn{1}{|c|}{ Patients } & $\mathrm{N}=65$ \\
\hline Male/female & $38 / 27$ \\
\hline Median age (Q1-Q3) & 72 Years (70-77) \\
\hline$>70$ Years & $48(74 \%)$ \\
\hline Performance status (N,\%) & \\
\hline 0 & $20(31 \%)$ \\
\hline 1 & $37(58 \%)$ \\
\hline$>1$ & $7(11 \%)$ \\
\hline NA & 1 \\
\hline Median WBC count (Q1-Q3) & $2.3 \times 10 \% / \mathrm{L}(1.6-4.7)$ \\
\hline Median platelet count (Q1-Q3) & $43 \times 10 \% / \mathrm{L}(19-73)$ \\
\hline Median marrow blast percentage (Q1-Q3) & $31 \%(20-53)$ \\
\hline Disease subsets (N, \%) & \\
\hline Previously untreated AML & $42(65 \%)$ \\
\hline Relapsed/refractory AML & $13(20 \%)$ \\
\hline High-risk MDS & $10(15 \%)$ \\
\hline Cytogenetics (N, \%) & \\
\hline Standard & $70(52 \%)$ \\
\hline Unfavorable * & 7 \\
\hline NA & \\
\hline
\end{tabular}

* unfavorable karyotypes were defined as -7 , del( $7 q),-5,3 q$ abnormality, or complex (5 anomalies or more); NA: not available.

No complete (CR) or partial (PR) remission was observed after the first cycle. Among the 45 patients who received the first 3 cycles, $8(18 \%)$ were in CR and $3(7 \%)$ in PR at that time (Table 2). Among the 34 patients who received the six planned cycles, $13(38 \%)$ achieved CR and $2(6 \%)$ achieved PR (Table 2). Best responses were, however, $14 \mathrm{CR}$ and $3 \mathrm{PR}(26 \%)$, as some patients lost their response between cycle 3 and 6 . Responses were seen within the three eligibility subsets: $11 \mathrm{CR}$ and $2 \mathrm{PR}$ in newly-diagnosed elderly patients, $2 \mathrm{CR}$ and $1 \mathrm{PR}$ in relapsed/refractory patients, and $1 \mathrm{CR}$ in high-risk MDS patients $(\mathrm{P}=0.47)$. Among the 15 patients alive in response after cycle 6,14 patients received further maintenance treatments with AZA alone (7 patients) or low-dose cytara- 
Table 2. Treatment compliance and responses

\begin{tabular}{|c|c|c|c|c|c|c|c|c|c|c|}
\hline \multirow{2}{*}{$\begin{array}{l}\text { After cycle } \\
\mathrm{N}\end{array}$} & \multirow{2}{*}{$\begin{array}{l}\text { Patients } \\
\mathrm{N}\end{array}$} & \multirow{2}{*}{$\begin{array}{l}\mathrm{CR} \\
N(\%)\end{array}$} & \multirow{2}{*}{$\begin{array}{l}P R \\
N(\%)\end{array}$} & \multirow{2}{*}{$\begin{array}{l}\text { Stable } \\
\mathrm{N}(\%)\end{array}$} & \multirow{2}{*}{$\begin{array}{l}\text { Progression } \\
N(\%)\end{array}$} & \multirow[t]{2}{*}{$\mathrm{NA}^{*}$} & \multicolumn{4}{|c|}{ Reasons for treatment discontinuation $(\mathrm{N})$} \\
\hline & & & & & & & $\begin{array}{l}\text { Patient } \\
\text { decision }\end{array}$ & $\begin{array}{l}\text { Disease } \\
\text { progression }\end{array}$ & $\begin{array}{l}\text { Severe } \\
\text { toxicity }\end{array}$ & Death \\
\hline 0 & 65 & - & - & - & - & - & 1 & 0 & 0 & 2 \\
\hline 1 & 62 & $0(0 \%)$ & $0(0 \%)$ & $38(61 \%)$ & $10(16 \% 0$ & $14(23 \%)$ & 1 & 1 & 2 & 7 \\
\hline 2 & 51 & - & - & - & - & & 0 & 0 & 3 & 3 \\
\hline 3 & 45 & $8(18 \%)$ & $3(7 \%)$ & $26(57 \%)$ & $8(18 \%)$ & $0(0 \%)$ & 0 & 4 & 0 & 1 \\
\hline 4 & 40 & - & - & - & - & & 1 & 1 & 0 & 2 \\
\hline 5 & 36 & - & - & - & - & & 0 & 2 & 0 & 0 \\
\hline 6 & 34 & $13(38 \%)$ & $2(6 \%)$ & $14(41 \%)$ & $5(15 \%)$ & $0(0 \%)$ & - & - & - & - \\
\hline
\end{tabular}

* response was not recorded after cycle 1 in 14 patients still on study.

bine (7 patients). At the 6-cycle evaluation time, the cumulative incidence of CR + PR was 27\% (95\% CI: $26-28 \%$ ), while that of treatment discontinuation was $15.5 \%(95 \%$ CI: $14.5-16.5 \%)$ and that of death before response was $31 \%$ (95\% CI: 30-32\%).

Median PB neutrophil count, platelet count, and $\mathrm{Hb}$ level observed during therapy in the 34 patients who received the 6 planned treatment cycles are shown in Figure 1 according to the 6-month response (15 responding and 19 non-responding patients). As indicated, platelet count improvement was the earliest feature observed in responding patients. Stable PB counts or partial improvements were, however, observed in non-responding patients. With respect to erythroid response, $75 \%$ of the responders and $36 \%$ of the non-responders met criteria for ER after
6 cycles. Erythroid response was never observed after the first cycle, but $10 \%$ of the responders and $12.5 \%$ of the non-responders reached it after 3 cycles.

Factors usually associated with the outcome of AML/ MDS patients (age, PS, cytogenetics, and disease status) predicted death before response during therapy. These factors, including cytogenetics, did not, however, predict the response. The only factor associated with a lower response incidence was a low platelet count $(18 \% \mathrm{CR}+\mathrm{PR}$ in the 24 patients with initial platelet count $<50.10^{9} / \mathrm{L}$ ). In addition, early platelet recovery after the first cycle was significantly associated with a higher response rate $(\mathrm{P}<0.001$ for platelet count as a continuous variable). Response incidence reached $57 \%$ in patients with a platelet count of 100 x $10^{9} / \mathrm{L}$ or more after the first cycle compared to $12 \%$ in other patients $(\mathrm{P}=0.001)$.
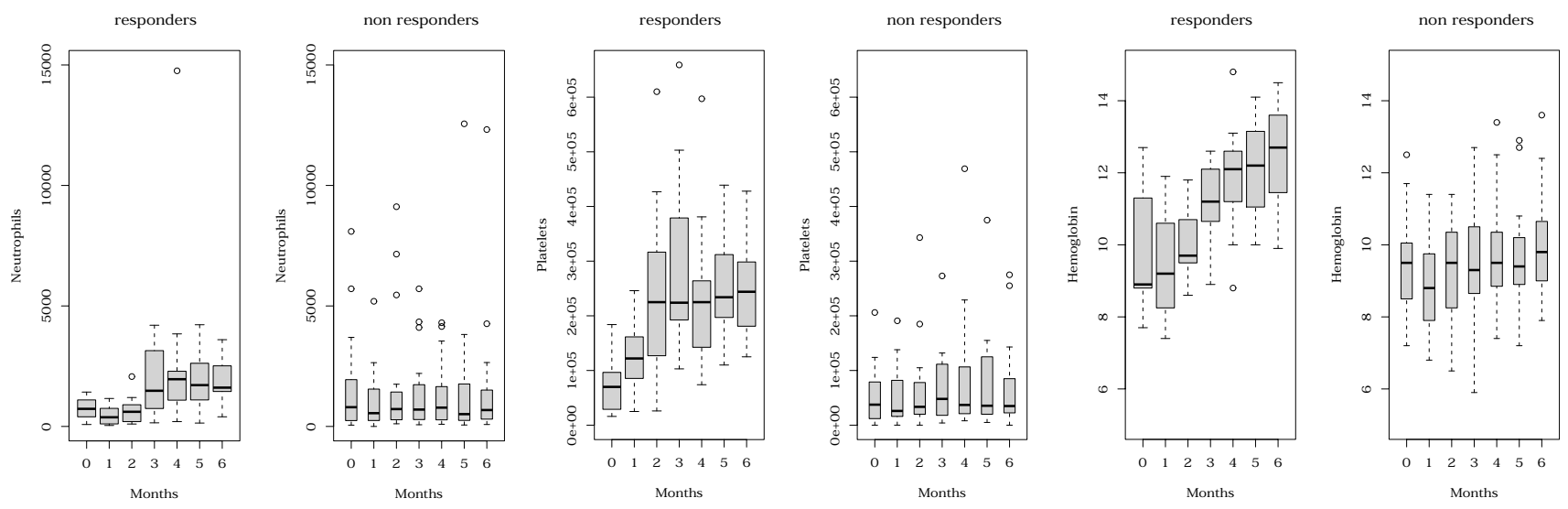

Fig. 1. Kinetics of peripheral blood neutrophil count, platelet count, and hemoglobin level during the treatment period. The evolution of peripheral blood neutrophil count $\left(/ \mathrm{mm}^{3}\right)$, platelet count $\left(/ \mathrm{mm}^{3}\right)$, and hemoglobin level $(\mathrm{g} / \mathrm{dL})$ is shown in the 34 patients who may receive the planned 6 treatment cycles, according to the response (15 CR + PR patients versus 19 non-responding patients). 


\section{Toxicity}

Main adverse events are reported in Table 3. If one except fatigue, infections, and hemorrhages usually observed in AML patients, the toxicities observed may readily be related to one of the three drugs administered. Somnolence and confusion related to VPA led to amend the starting VPA dose after the first 11 patients. Gastro-intestinal events were probably related to AZA, as were pain at the AZA injection sites and fatigue. Mucosal dryness is a well-known side effect of ATRA. In the 34 patients who received the 6 cycles, re-hospitalization rate was $29 \%$, $38 \%, 23 \%, 18 \%, 15 \%$, and $15 \%$ after cycle 1 to 6 , respectively.

\section{Survival}

Figure 2A shows OS in the 65 enrolled patients, according to the eligibility subsets. Median OS was 12.4 months for the whole patient cohort, with a significant difference between naïve AML/MDS patients and relapsing patients (18.1 versus 2.9 months; $\mathrm{P}=0.0024$ ). Median $\mathrm{OS}$ of the 17 responders was 19.6 months. In the 34 patients who received the 6 planned cycles, OS from 6-month evaluation was not significantly different between responding and non-responding patients (Figure 2B), meaning that the survival of patients who were still on therapy at that time did not seem to be significantly influenced by CR or PR obtention. Factors previously shown to be associated with death during therapy (age, PS, cytogenetics, and disease status) were also predictive of OS. Based on multivariable Cox model, only PS and unfavorable cytogenetics were associated with a shorter OS.

\section{Genome methylation}

Baseline methylation profiles were available in 28 patients. After excluding sexual chromosome-related sites, 1421 regulatory regions were analyzed. Methylation profiles were bimodal with 454 sites with a median methylation of $50 \%$ or more $(32 \%)$. Methylation profiles were relatively similar among patients and unsupervised clustering did not allow identifying subgroups with different patterns, even when focusing on hypermethylated loci (data not shown). Similarly, supervised clustering did not allow to allocate specific signatures to various patient subsets defined by age, gender, PS, WBC, platelet count, percentage of marrow blasts, disease status, cytogenetics, or even response to therapy. After adjustment for multiple testing, only one site showed significant correlation with WBC $(P M P 22, \mathrm{P}=0.04)$ and another with marrow blast percentage (TFDP $1, \mathrm{P}=0.01)$, but no site was significantly differently methylated at baseline between responders and non-responders.
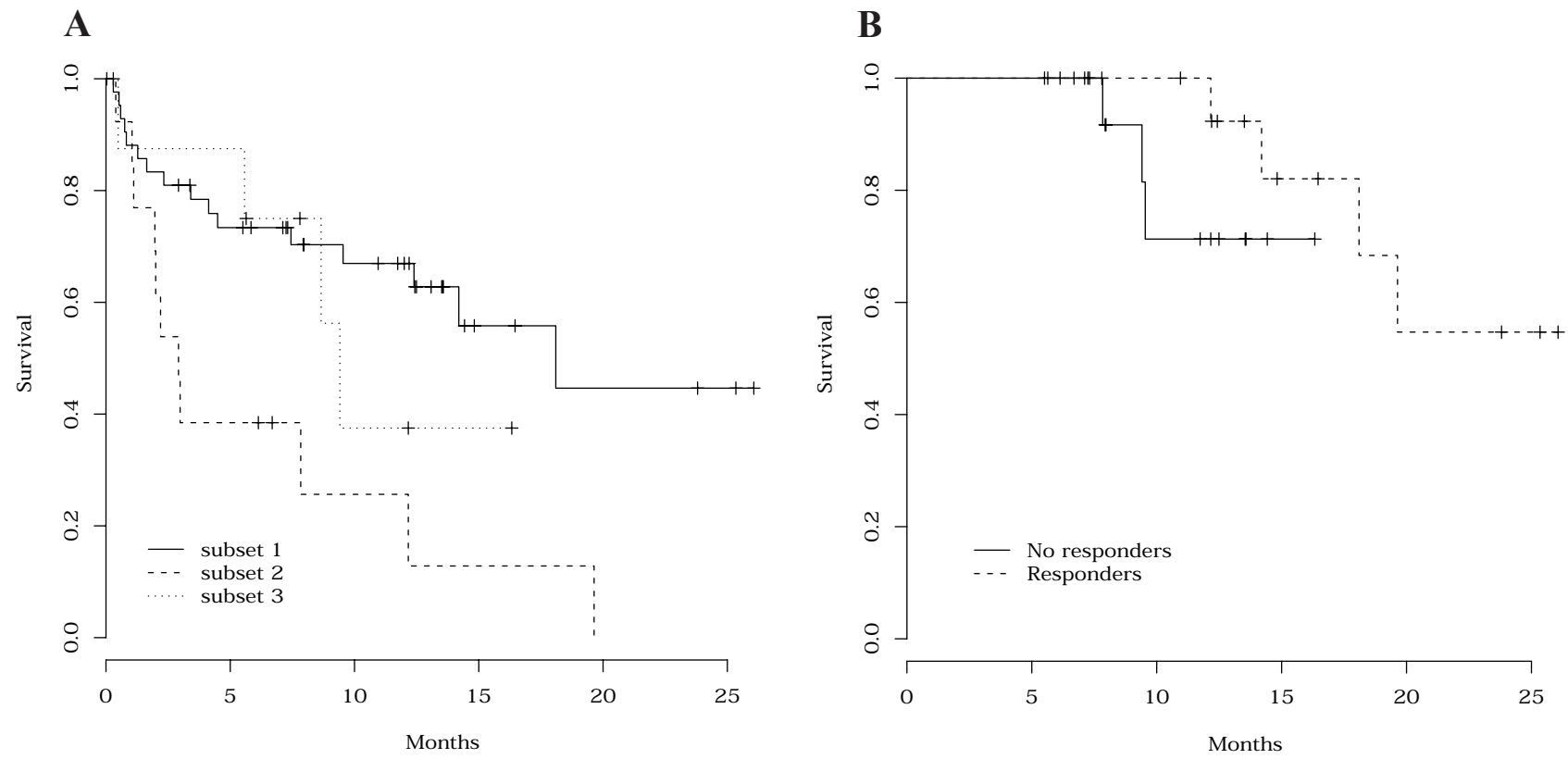

Fig. 2. Overall survival

(A) OS from study inclusion according to the three eligibility subsets. OS was significantly shorter in patients relapsing after prior intensive chemotherapy (subset 2) than in naïve patients with either AML (subset 1) or high-risk MDS (subset 3 ) ( $P=$ 0.0024). (B) OS following the 6-month evaluation according to the response observed at 6 months. In the 34 patients who received the 6 planned cycles, OS after the 6 -month evaluation was not significantly different between responding $(N=15)$ and non-responding $(\mathrm{N}=19)$ patients. 
Table 3. Adverse events

\begin{tabular}{|l|c|c|}
\hline Events & $\begin{array}{c}\text { Number of } \\
\text { events }\end{array}$ & $\begin{array}{c}\text { Cycle of occur- } \\
\text { rence } \\
\text { (Mean } \pm \text { SD) }\end{array}$ \\
\hline Confusion & 33 & $1.7 \pm 1.4$ \\
\hline Fatigue & 20 & $2.0 \pm 1.5$ \\
\hline Somnolence & 12 & $1.3 \pm 1.4$ \\
\hline Constipation & 13 & $1.0 \pm 1.1$ \\
\hline Nausea / Vomiting & 10 & $2.5 \pm 1.7$ \\
\hline Hemorrhage & 13 & $2.0 \pm 1.4$ \\
\hline SC puncture site reaction & 9 & $1.7 \pm 1.9$ \\
\hline Mucosa dryness & 8 & $1.7 \pm 2.0$ \\
\hline Infection & & $2.0 \pm 3.3$ \\
\hline All events & 76 & - \\
\hline Pneumonia & 13 & - \\
\hline Septicemia & 2 & - \\
\hline Fungal infection * & & \\
\hline
\end{tabular}

* two invasive Aspergillus sp. infections.

Eight patients had an additional methylation profile obtained after 1 to 3 treatment cycles. Four of these patients achieved a response at 6-month evaluation (2 CR and 2 PR), while four patients did not respond. Table 4A shows the sites that were strongly differentially demethylated during therapy between responders and non-responders.
All these genes (FZD9, ALOX12, HPN, and CALCA) were hypermethylated at baseline and demethylated during therapy in responding patients, even if not reaching the statistical significance level after adjustment for multiple testing.

\section{Induction of differentiation}

There was no evidence supporting the hypothesis of ATRA-induced differentiation restoration, even in responding patients. Morphological features suggesting in vivo differentiation of AML blasts, reminiscent of those observed in APL patients under ATRA treatment, were observed in one CR patient only. Unfortunately, this patient did not have cytogenetic aberration that could have been monitored to further support this hypothesis. No clinical symptoms suggesting any differentiation syndrome were noted. In addition, no clear demethylation was observed at various retinoic acid target gene loci during therapy. Retinoic acid receptor alpha $(R A R A)$ and beta $(R A R B)$ gene promoters were rather hypomethylated at baseline and no significant change in their methylation levels was observed during therapy (Table 4B). Although demethylation of the two $R B P 1$ loci appeared slightly superior in responding than in non-responding patients, no clear differences between responding and non-responding patients were observed for three other CDKN1A, RBP1, and ETS1 retinoic acid target genes.

Table 4. Methylation changes according to the response to therapy

\begin{tabular}{|l|c|c|c|c|c|c|}
\hline & \multicolumn{3}{|c|}{ Non-responding patients* $(\mathbf{n}=\mathbf{4})$} & \multicolumn{3}{|c|}{ Responding patients $^{* *}(\mathbf{n}=\mathbf{4})$} \\
\hline Methylation level & Before Tx & After Tx & $\Delta$ & Before Tx & After Tx & $\Delta$ \\
\hline FZD9 & $75 \%$ & $77 \%$ & $2 \%$ & $57 \%$ & $34 \%$ & $-23 \%$ \\
\hline ALOX12 & $88 \%$ & $90 \%$ & $2 \%$ & $77 \%$ & $55 \%$ & $-22 \%$ \\
\hline HPN & $76 \%$ & $73 \%$ & $-3 \%$ & $71 \%$ & $45 \%$ & $-26 \%$ \\
\hline CALCA & $43 \%$ & $43 \%$ & $0 \%$ & $60 \%$ & $37 \%$ & $-23 \%$ \\
\hline
\end{tabular}

(A) Regulatory regions associated with the largest differences in demethylation between responding and non-responding patients during the therapy.

\begin{tabular}{|l|c|c|c|c|c|c|}
\hline & \multicolumn{2}{|c|}{ Non-responding patients* $(\mathbf{n}=\mathbf{4})$} & \multicolumn{2}{|c|}{ Responding patients ${ }^{* *}$ (n=4) } \\
\hline Methylation level & Before Tx & After Tx & $\Delta$ & Before Tx & After Tx & $\Delta$ \\
\hline RARA & $20 \%$ & $20 \%$ & $0 \%$ & $19 \%$ & $14 \%$ & $-5 \%$ \\
\hline RARA & $43 \%$ & $43 \%$ & $0 \%$ & $36 \%$ & $46 \%$ & $10 \%$ \\
\hline RARA & $47 \%$ & $51 \%$ & $4 \%$ & $47 \%$ & $40 \%$ & $-7 \%$ \\
\hline RARB & $4 \%$ & $4 \%$ & $0 \%$ & $4 \%$ & $5 \%$ & $1 \%$ \\
\hline RARB & $13 \%$ & $9 \%$ & $-4 \%$ & $19 \%$ & $12 \%$ & $-7 \%$ \\
\hline CDKN1A & $8 \%$ & $7 \%$ & $-1 \%$ & $8 \%$ & $10 \%$ & $2 \%$ \\
\hline CDKN1A & $4 \%$ & $5 \%$ & $1 \%$ & $6 \%$ & $5 \%$ & $-1 \%$ \\
\hline RBP1 & $6 \%$ & $7 \%$ & $1 \%$ & $7 \%$ & $8 \%$ & $1 \%$ \\
\hline RBP1 & $7 \%$ & $7 \%$ & $0 \%$ & $13 \%$ & $4 \%$ & $-9 \%$ \\
\hline RBP1 & $22 \%$ & $17 \%$ & $-5 \%$ & $40 \%$ & $26 \%$ & $-14 \%$ \\
\hline ETS1 & $25 \%$ & $23 \%$ & $-2 \%$ & $31 \%$ & $33 \%$ & $2 \%$ \\
\hline ETS1 & $3 \%$ & $4 \%$ & $1 \%$ & $4 \%$ & $4 \%$ & $0 \%$ \\
\hline
\end{tabular}

(B) Methylation changes observed at RA target gene regulatory regions.

* none of these four patients achieved CR or PR at 6-month evaluation;

** 2 patients achieved $\mathrm{CR}$ and 2 patients achieved PR at 6-month evaluation;

$\Delta$ indicates the decrease in gene promoter methylation level observed during therapy (Tx). 


\section{DISCUSSION}

We report here a $26 \%$ response rate including $22 \% \mathrm{CR}$ associated with AZA/VPA/ATRA treatment in patients with high-risk AML or MDS. Even if selected, the 65 patients enrolled were clearly at high risk of treatment failure: their median age was over 70 years and, more importantly, half of them had very unfavorable cytogenetic features. Similar response rates have been reported using various combination of the same drugs, even if using different schedules [18-19]. In the first study from the M.D. Anderson Cancer Center (MDACC) which included a much shorter ATRA exposure (5 days per cycle, from day 3 to 7 ), the overall CR rate was $23 \%$ [18]. As in the present study, responses were observed across the different risk subsets including unfavorable cytogenetics. In the British study which added theophylline to AZA/VPA/ATRA as a fourth pro-differentiating agent, the overall CR/CRi/PR rate was 33\% [19].

It appears thus that ATRA does not add any significant clinical benefit to treatments based on epigenetic modifying drugs. Various 2-drug or even 1-drug regimens with DNA methyltransferase inhibitors and/or HDACi have antiAML efficacy $[2-10,20]$ and response rates observed in these three ATRA-containing studies are not clearly superior. Furthermore, similar response rates were observed when using either 5 days of ATRA administration per treatment cycle, as in the MDACC study [8], or 21 days, as in the present study. In addition, we were unable to provide observations supporting a significant differentiating effect of ATRA when combined to AZA/VPA in such non-APL patients.

Whether the superiority of AZA/HDACi combinations over the single-agent AZA therapy remains questionable, as no controlled study has yet prospectively addressed this issue. Some in vitro data are in favor of additive or synergistic effects when adding VPA to a DNA methyltransferase inhibitor [21]. The single randomized Phase 2 study which has addressed this issue in MDS/AML patients has used decitabine but not AZA, and reported only marginal response rate and time to response improvements without impact on survival [22]. Of interest, combinations of azacitidine with newer and potentially less toxic HDACi, such as vorinostat or entinostat, have also been reported as associated with good response rates [23-24].

The present study provides two additional important clinical observations. The first one is the prognostic value of a rapid platelet count recovery, often observed as soon as during the first cycle in responders and suggesting a direct effect of any component of the treatment on the megakaryocytic lineage. The second one is the apparent good outcome of patients who did not reach CR or PR but may receive the whole planned treatment. Similar results were recently reported in high-risk MDS patients [8]. This confers an unusual feature to AZA, which appears as a drug able to significantly prolong survival even in the absence of hematological response.

Maybe due to the low number of patients studied, we were unable to find specific methylation profile signatures that distinguished responders from non-responders. We nonetheless identified a set of four genes that were markedly demethylated in responding patients, while unchanged in non-responding patients. Interestingly, these four genes (FZD9, ALOX12, HPN, and CALCA) have been recently reported as aberrantly methylated in MDS/AML patients during the progression from MDS to AML [25]. Among these genes, FZD 9 is a receptor of Wnt and a putative tumor suppressor gene located on chromosome 7. It is thus tempting to consider that patients responding to epigenetic modulation might somehow "return" to a less advanced pre-leukemic state. In the British study mentioned above [19], it was observed that some patients may reach CR with good restoration of marrow progenitor quantity and quality, while still harboring persistent malignant stem cells [19]. If confirmed, these observations should encourage further approaches to maintain long lasting responses in these patients, including stem cell transplantation, immunomodulators, or even vaccination.

In conclusion, as shown by the median OS reported here, epigenetic modulation deserves now direct randomized comparisons to other conventional care regimens in older patients with AML, at least in those presenting previously untreated disease and relatively low blast count. Identification of reliable biomarkers that could predict response to these new therapies remains an important issue to select patients most likely to derive a prolonged benefit from these treatments.

\section{PATIENTS AND METHODS}

\section{Study design and treatments}

The study (ClinicalTrials.gov ID, NCT00339196) was approved by the Ethics Committee of the Pitié-Salpêtrière Hospital, sponsored by the Délegation à la Recherche Clinique (DRRC ID, P050202), and conducted between 2006 and 2007 in 9 French centers. All patients signed informed consent in accordance to the Declaration of Helsinki. Patients were planned to receive six monthly cycles of AZA/VPA/ATRA. AZA was given subcutaneously at $75 \mathrm{mg} / \mathrm{m}^{2} / \mathrm{d}$ in combination with oral VPA at 35 to $50 \mathrm{mg} /$ $\mathrm{kg} / \mathrm{d}$, both for 7 days (day 1 to 7). ATRA was then given orally at $45 \mathrm{mg} / \mathrm{m}^{2} / \mathrm{d}$ from day 8 to 28 . Patients were admitted in hospitals for cycle 1 , while they were treated on an outpatient basis for cycles 2-6, which were repeated whatever peripheral blood (PB) counts but not earlier than every 4 weeks. At the onset of the study, VPA was started at $50 \mathrm{mg} / \mathrm{kg} / \mathrm{d}$ in all patients. After enrolment of the first 11 patients, excessive VPA-induced neurological toxicity observed in some patients led the independent Data Safety 
and Monitoring Committee to recommend a $35 \mathrm{mg} / \mathrm{kg} / \mathrm{d}$ VPA starting dose for the first cycle, that could then be increased to $50 \mathrm{mg} / \mathrm{kg} / \mathrm{d}$ for subsequent cycles if clinically tolerated. Supportive care measures including antibiotics, antiemetics, and growth factors were allowed if clinically indicated and according to institutional guidelines. After the 6th cycle, responding patients could receive further maintenance treatments.

\section{Eligibility criteria}

High-risk AML was defined as newly-diagnosed previously untreated AML in patients aged 70 years or more unlikely to benefit from standard intensive chemotherapy (subset 1) or relapsed/refractory AML in patients with a first CR duration $<18$ months and/or post-MDS AML (subset 2). High-risk MDS was defined as refractory anemia with excess blasts or refractory anemia with excess blasts in transformation with an intermediate-2 or high International Prognostic Scoring System (IPSS) score [15] (subset 3). Eligibility criteria also included an ECOG performance status (PS) score not higher than 3 and adequate hepatic and renal functions. Patients must have been off chemotherapy or other investigational therapy for at least 4 weeks prior study entry and not previously treated with AZA, VPA, or ATRA. Patients with APL or central nervous system leukemic involvement, or patients with active or uncontrolled infection were excluded, as well as those with a white blood cell count $(\mathrm{WBC}) \geq 30 \times 10^{9} / \mathrm{L}$. Pre-treatment with hydoxyurea was allowed, but had to be interrupted at least 48 hours prior to study entry.

\section{Cytogenetic and response classification}

Unfavorable cytogenetics was defined as -7 , del(7q), $-5,3 q$ abnormality, or complex (5 anomalies or more). All other karyotypes were classified in a standard-risk group. Bone marrow and $\mathrm{PB}$ response was assessed after cycle 1, 3 , and 6 , and classified according to the International Working Group (IWG) AML criteria [16]. Erythroid response (ER) was defined according to IWG MDS criteria [17].

\section{Genome methylation assay}

Marrow samples were obtained at baseline in 28 patients and under therapy in 8 patients. Mononuclear cells were isolated using Ficoll density gradient centrifugation (Eurobio, Les Ulis, France). Genomic DNA was prepared using the DNA Blood Mini Kit (Qiagen, Courtaboeuf, France) and then subjected to sodium bisulfite conversion using the EZ DNA Methylation Kit (Zymo Reseach, Orange, CA). DNA methylation profiles were determined using the GoldenGate Methylation Cancer Panel I (Illumina, San Diego, CA). Briefly, bisulfite-converted DNAs are biotinylated, hybridized to query oligos, and washed. The hybridized oligos are then extended and ligated to create amplifiable templates. The PCR that follows uses fluorescently labeled universal PCR primers. The resulting PCR products were hybridized to a bead array at sites bearing complementary address sequences. These hybridized targets contained a fluorescent label that tagged methylated or unmethylated sequences at a given locus. Methylation status of the interrogated $\mathrm{CpG}$ sites was determined by comparing the ratio of the fluorescent signal from the methylated allele to the sum from the fluorescent signals of both methylated and unmethylated alleles yielding a percentage of methylation at each site. The GoldenGate Methylation Cancer Panel I assay probes $1505 \mathrm{CpG}$ sites from the 5 ' regulatory regions of 807 cancer-associated genes on 23 chromosomes.

\section{Statistical methods}

Analysis was performed on the intent-to-treat basis. Cumulative incidences of response were estimated considering treatment discontinuation and death before response as competing risks and compared with the Gray test. Overall survival (OS) was estimated by the Kaplan-Meier method, with reference date of November 15th, 2008. Survival comparisons were based on Cox proportional hazards models. The following factors were analyzed for their prognostic value: gender, age, PS, WBC, platelet counts, marrow blast percentage, cytogenetics, and relapsed/ refractory status. All statistical tests were two-sided. For DNA methylation assay analysis, the 84 regulatory regions located on sexual chromosomes were excluded. The raw profiles were normalized using quantile normalization. Unsupervised clustering was applied using the euclidean distance. Initial methylation profiles were correlated with baseline characteristics and response at 6 months using the Spearman correlation coefficient. Changes in methylation levels were investigated in a subset of patients for whom a second methylation profile was available after initiation of treatment. Multiple testing correction was applied using the Bonferroni single step method for P values. All analyses were performed on SAS 9.1 (SAS, Cary, NC) and R 2.8.0 software packages (http://www.R-project.org).

\section{ACKNOWLEDGEMENTS}

Authors are grateful to the Délégation Régionale à la Recherche Clinique (DRRC) of Paris Ile-de-France and the Département de Biostatistique et Informatique Médicale (DBIM) of the Hôpital Saint-Louis, Paris, for their implication in study sponsoring and monitoring. Authors are indebted to Fabienne Treilhou and Karine Celli-Lebras for their inestimable help in data collection and cleaning. The study was supported by the Institut National de la Santé et de la Recherche Médicale (INSERM), the Direction de l'Hospitalisation et de l'Organisation des Soins (DHOS) 
from the French Government, the Région Ile-de-France, and the Fondation de France.

Drugs were kindly provided, free of charge, by Celgene (Paris, France) for 5-azacytidine $\left(\operatorname{Vidaza}^{\circ}\right)$ and by Roche (Neuilly/Seine, France) for all-retinoïc acid $\left(\right.$ Vesanoïd $\left.^{\circ}\right)$. Celgene (Boudry, Switzerland) provided grants to perform Genome Methylation Assay.

\section{Author's contributions}

The study was designed by E.R., L.D., and H.D. E.R. and A.dL. participated in study monitoring, data collection and cleaning. E.R., A.dL., C.R., P.T., JP.M., O.R., C.G., S.M., P.R., JV.M., P.F., and H.D. enrolled and treated the patients. O.M. centrally reviewed all cytogenetic results. A.C., M.V. and C.C. performed the genome analyses. PY.B. and S.C. performed the statistical analyses. E.R. and H.D. participated in the study analysis and wrote the manuscript. All the authors approved the final manuscript.

\section{AUTHOR'S DISCLOSURE}

C.G., P.F., and H.D. have received lecture fees from speaking at the invitation of Celgene (5-azacitidine, Vidaza $^{\mathrm{TM}}$ ). C.G., P.F. and H.D. have participated to paid advisory boards organized by Celgene (5-azacitidine, Vidaza $^{\mathrm{TM}}$ ). E.R., C.G., P.F., and C.C. have received grants support from Celgene (5-azacitidine, Vidaza ${ }^{\mathrm{TM}}$ ).

\section{REFERENCES}

1. Herman JG, Baylin SB. Mechanisms of disease: gene silencing in cancer in association with promoter hypermethylation. N Engl J Med 2003; 349:2042-2054.

2. Silverman LR, Demakos EP, Peterson BL, Kornblith AB, Holland JC, Odchimar-Reissig R, Stone RM, Nelson D, Powell BL, DeCastro CM, Ellerton J, Larson RA, Schiffer CA, Holland JF. Randomized controlled trial of azacitidine in patients with the myelodysplastic syndrome: a study of the cancer and leukemia group B. J Clin Oncol 2002;20:24292440.

3. Sudan N, Rossetti JM, Shadduck RK, Latsko J, Lech JA, Kaplan RB, Kennedy M, Gryn JF, Faroun Y, Lister J. Treatment of acute myelogenous leukemia with outpatient azacitidine. Cancer 2006;107:1839-1843.

4. Cashen AF, Schiller GJ, O’Donnell MR, Larsen JS, Baranwal A, DiPersio JF. Preliminary results of a multicenter Phase II trial of 5-day decitabine as front-line therapy for elderly patients with acute myeloid leukemia. Blood 2008 (ASH Meeting Abstracts);112:560.

5. Lübbert $M$, Schmid M, Rüter B, Germing U, Rethwisch V, Ganser A, Platzbecker U, Galm O, Brugger W, Wijermans PW, Schmoor C, Döhner H. Continued treatment with an outpatient maintenance schedule of decitabine in older AML patients ineligible for induction chemotherapy: results of the 00331 Phase II multicenter trial. Blood 2008 (ASH Meeting Abstracts);112:2965.

6. Blum W, Klisovic R, Liu S,Garzon R, Kefauver C, Liu Z, Mickle J, Devine H, Devine S, Grever MR, Chan K, Villalona-Calero M, Byrd JC, Marcucci G. Preliminary results of a Phase II study of low dose decitabine as a single agent in older patients (age $\geq 60$ ) with previously untreated acute myeloid leukemia. Blood 2008 (ASH Meeting Abstracts);112:2957.

7. Al-Hali HK. The safety and efficacy of azacitidine in patients with newly-diagnosed and refractory/relapsed AML not eligible for or resistant to chemotherapy: a multicenter Phase I/II study of the East German Haematology and Oncology Study Group (OSHO). Haematologica 2009 (EHA Meeting Abstracts);94:343.

8. Fenaux P, Mufti GJ, Hellstrom - Lindberg E, Santini V, Finelli C, Giagounidis A, Schoch R, Gattermann N, Sanz G, List A, Gore SD, Seymour JF, Bennett JM, Byrd J, Backstrom J, Zimmerman L, McKenzie D, Beach C, Silverman LR; International Vidaza High-Risk MDS Survival Study Group. Efficacy of azacitidine compared with that of conventional care regimens in the treatment of higher-risk myelodysplastic syndromes : a randomized open-label Phase III study. Lancet Oncol $2009 ; 10: 223-232$.

9. Fenaux P, Mufti GJ, Hellström-Lindberg E, Santini V, Gattermann N, Germing U, Sanz G, List AF, Gore S, Seymour JF, Dombret H, Backstrom J, Zimmerman L, McKenzie D, Beach CL, Silverman LR. Azacitidine improves overall survival in WHO acute myeloid leukemia in elderly patients with low bone marrow blast count. J Clin Oncol. 2010 ;28:562-569.

10. Kitaruma K, Hoshi S, Koike M, Kiyoi H, Saito H, Naoe T. Histone deacetylase inhibitor but not arsenic trioxide differentiates acute promyelocytic leukaemia cells with $\mathrm{t}(11 ; 17)$ in combination with all-trans retinoic acid. Br J Haematol 2000;108:696-702.

11. Warrell RP Jr, He LZ, Richon V, Calleja E, Pandolfi PP. Therapeutic targeting of transcription in acute promyelocytic leukemia by use of an inhibitor of histone deacetylase. J Nat Cancer Inst 1998;90:1621-1625.

12. Phiel CJ, Zhang F, Huang EY, Guenther MG, Lazar MA, Klein PS. Histone deacetylase is a direct target of valproic acid, a potent anticonvulsant, mood stabilizer, and teratogen. J Biol Chem 2001;276:36734-36741.

13. Kuendgen A, Strupp C, Aivado M, Bernhardt A, Hildebrandt B, Haas R, Germing U, Gattermann N. Treatment of myelodysplastic syndromes with valproic acid alone or in combination with all-trans retinoic acid. Blood 2004;104:1266-1269.

14. Raffoux E, Chaibi P, Dombret H, Degos L. Valproic acid and all-trans retinoic acid for the treatment of elderly patients with acute myeloid leukemia. Haematologica 2005;90:986988.

15. Greenberg P, Cox C, LeBeau MM, Fenaux P, Morel P, Sanz G, Vallespi T, Hamblin T, Oscier D, Ohyashiki K, Toyama K, Aul C, Mufti G, Bennett J. International scoring system for evaluating prognosis in myelodysplastic syndromes. Blood 1997;89:2079-2088.

16. Cheson BD, Bennett JM, Kopecky KJ, Bûchner T, William CL, Estey EH, Schiffer CA, Doehner H, Tallman MS, Lister 
TA, Lo-Coco F, Willemze R, Biondi A, Hiddemann W, Larson RA, Löwenberg B, Sanz MA, Head DR, Ohno R, Bloomfield CD.Revised recommendations of the International Working Group for diagnosis, standardization of response criteria, treatment outcomes, and reporting standards for therapeutic trials in acute myeloid leukemia. J Clin Oncol 2003;21:46424649.

17. Cheson BD, Greenberg PL, Bennett JM, Lowenberg B, Wijermans PW, Nimer SD, Pinto A, Beran M, de Witte TM, Stone RM, Mittelman M, Sanz GF, Gore SD, Schiffer CA, Kantarjian H. Clinical application and proposal for modification of the International Working Group (IWG) response criteria in myelodysplasia. Blood 2006;108:419-425.

18. Soriano AO, Yang H, Faderl S, Estrov Z, Giles F, Ravandi F, Cortes J, Wierda WG, Ouzounian S, Quezada A, Pierce S, Estey EH, Issa JP, Kantarjian HM, Garcia-Manero G. Safety and clinical activity of the combination of 5-azacitidine, valproic acid, and all-trans retinoic acid in patients with acute myeloid leukemia and myelodysplastic syndrome. Blood 2007; 110:2302-2308.

19. Craddock C, Goardon N, Griffiths M, Siddique S, Cavenagh J, Vyas P. 5' azacitidine in combination with valproic acid induces complete remissions in patients with high risk acute myeloid leukaemia but does not eradicate clonal leukaemic stem/progenitor cells. Haematologica 2009 (EHA Meeting Abstracts);94:429.

20. Garcia-Manero G, Kantarjian HM, Sanchez-Gonzalez B, Yang H, Rosner G, Verstovsek S, Rytting M, Wierda WG, Ravandi F, Koller C, Xiao L, Faderl S, Estrov Z, Cortes J, O'brien S, Estey E, Bueso-Ramos C, Fiorentino J, Jabbour E, Issa JP. Phase $1 / 2$ study of the combination of 5-aza-2'deoxycytidine with valproic acid in patients with leukemia. Blood 2006, 108: 3271-3279.

21. Yang H, Hoshino K, Sanchez-Gonzalez B, Kantarjian H, Garcia-Manero G. Antileukemia activity of the combination of 5-aza-2'-deoxycytidine with valproic acid. Leukemia Research 2005;29:739-748.

22. Issa JP, Castoro R, Ravandi-Kashani F, Faderl S, Huang X, Estey E, Borthakur G, Morris G, Garcia-Manero G, Kantarjian H. Randomized Phase II study of combined epigenetic therapy: decitabine vs. decitabine and valproic acid in MDS and AML. Blood 2008 (ASH Annual Meeting Abstracts);112:228.

23. Silverman LR, Verma A, Odchimar-Reissig R, LeBlanc A, Najfeld V, Gabrilove J, Isola L, Espinoza_Delgado I, Zwiebel J. A phase I trial of epigenetic modulators vorinostat, in combination with azacitidine (azaC) in patients with the myelodysplastic syndrome (MDS) and acute myeloid leukemia (AML): a study of the New York Cancer Consortium. Blood 2008 (ASH Annual Meeting Abstracts);112:3656.

24. Fandy TE, Herman JG, Kerns P, Jiemjit A, Sugar EA, Choi SH, Yang AS, Aucott T, Dauses T, Odchimar-Reissig R, Licht J, McConnell MJ, Nasrallah C, Kim MK, Zhang W, Sun Y, Murgo A, Espinoza-Delgado I, Oteiza K, Owoeye I, Silverman LR, Gore SD, Carraway HE. Early epigenetic changes and DNA damage do not predict clinical response in an overlapping schedule of 5-azacitidine and entinostat in patients with myeloid malignancies. Blood 2009;114:34483458 .
25. Jiang Y, Dunbar A, Gondek L.P, Mohan S, Rataul M, O'Keefe C, Sekeres M, Saunthararajah Y, Maciejewski JP.Aberrant DNA methylation is a dominant mechanism in MDS progression to AML. Blood 2009;113:1315-1325. 